\title{
The Mediating Role of Rumination in the Relation Between Quality of Attachment Relations and Depressive Symptoms in Non-Clinical Adolescents
}

\author{
Tamara Ruijten · Jeffrey Roelofs $\cdot$ Lea Rood
}

Published online: 31 August 2010

(C) The Author(s) 2010. This article is published with open access at Springerlink.com

\begin{abstract}
This study examined associations between indices of the quality of attachment relationships of adolescents with parents and peers, rumination, and symptoms of depression. More specifically, a mediation model was investigated in which rumination was hypothesized to mediate the relation between quality of attachment relations and symptoms of depression. A total of 455 high school students completed a battery of questionnaires, including quality of attachment relations, rumination, and depression. Results showed that most indices of quality of attachment relations were significantly associated with rumination and symptoms of depression. When examining the relative contribution of these variables in explaining variance in depression symptoms, trust in parents, communication with peers, and alienation from peers accounted for a significant portion of the variance in depression scores. Finally, the relation between communication with peers and depressive symptoms was fully mediated by rumination, whereas partial mediation was found for the relations between parental trust and depressive symptoms, and between alienation from peers and depressive symptoms. Implications of the findings may be that the treatment of depression in adolescence should consist of both
\end{abstract}

J. Roelofs $(\square) \cdot$ L. Rood

Department of Clinical Psychological Science,

Maastricht University, Maastricht, The Netherlands

e-mail: j.roelofs@maastrichtuniversity.nl

T. Ruijten

Youth Department of the Community Mental Health Centre

(RIAGG Zuid), Roermond, The Netherlands cognitive interventions aimed at targeting ruminative thinking as well as a focus on interpersonal relationships of the adolescent with parents and peers.

Keywords Adolescence · Attachment - Depression · Rumination

\section{Introduction}

Adolescent depression is a serious disorder with prevalence rates ranging between 2.5 and $8.3 \%$ and a high risk of suicidality, recurrence and chronicity (Birmaher et al. 1996; Dunn and Goodyer 2006; Fombonne et al. 2001). In the past decade, the role of family factors in the development of depressive symptoms has received increased attention in research (Sander and Mc Carty 2005). One such factor is attachment. When caregivers are available to their child and respond in a loving and responsive way, the child develops a secure attachment bond with the caregivers and experiences confidence in self and others. A lack of protective and sensitive responding of the caregivers leads to a sense of insecurity and to an increase in levels of distress. Moreover, the child may develop an insecure attachment to the caregiver over time (Bowlby 1973, 1988). Self-report measures of attachment have been utilized to assess the quality of attachment relations in adolescence in comparison with the observational measures utilized in infancy (Gullone and Robinson 2005). Armsden et al. (1990) have found that depressed adolescents reported significantly less secure parent and peer attachment relations in terms of trust, communication, and alienation than their non-depressed counterparts (see also Green and Goldwyn 2002; Greenberg 1999). 
Recently, there has been interest in gaining a better understanding of the mechanisms by which attachment relationships are related to depressive symptoms. A good candidate here might be rumination. A ruminative response style can be defined as the tendency to engage in repetitive thinking about the depressive symptoms, as well as the causes and consequences of these symptoms (NolenHoeksema 1991, 1998).

A recent meta-analysis has shown that rumination is significantly associated with symptoms of depression in youth (Rood et al. 2009). There have been relatively few attempts to examine developmental antecedents of rumination. There is some evidence suggesting that people who report having psychologically over controlling parents, tend to engage in rumination in response to depressed mood (Spasojevic and Alloy 2002). For attachment, rumination has been found to mediate the pathway to depression in insecurely-attached adolescents, when confronted with stress involving romantic relationships (Margolese et al. 2005). Thus, the quality of the relationship between caregivers and children might determine to what extent the child becomes a ruminator.

The aim of the current study was to bring together research on attachment relations, rumination, and symptoms of depression. With respect to attachment, peer relations become more important during adolescence as more time is spent with friends. There is evidence to suggest that adolescents prefer friends over parents for their company, and as sources of comfort and emotional support, but parents continue to serve as bases of security (Hazan and Zeifman 1994). The current study focused on the quality of attachment relations (i.e., trust, communication, and alienation) rather than attachment status and included both parents and peers. Second, we examined the relative contribution of indices of quality of attachment relations in explaining variance in depressive symptoms. We hypothesized that quality of attachment relations to both parents and peers would account for a unique portion of the variance in depression scores. Finally, the current study examined rumination as a mediator in the relation between indices of quality of attachment relations and symptoms of depression. Alienation as an attachment relationship variable refers to interpersonal isolation and has some resemblance to lack of social support. Abela et al. (2004) found some evidence to suggest that rumination did not only mediate the relation between low social support and depressive symptoms, but also that social support mediated the relation between rumination and depression, as rumination may create a vicious cycle wherein rumination may lead to a negative view of the social environment resulting in depression. We therefore tested both mediation models. The findings may contribute to a more differentiated picture of what parent and peer attachment variables are associated with depression through the cognitive mechanism of rumination.

\section{Methods}

Participants and Procedure

A total of 455 adolescents (201 males, 254 females) participated in this study. Adolescents were recruited from three high schools in the Southern part of the Netherlands. Mean age of the adolescents was 14.3 years ( $\mathrm{SD}=1.3$, age range $12-18$ years). A total of $30 \%$ of the total sample attended pre-vocational secondary education, whereas $27 \%$ attended higher general secondary education and $43 \%$ pre-university education. The vast majority of the sample was Caucasian (97.8\%). Participants and their parents were informed about the study protocol and consent was obtained from both the adolescents and their parents. A battery of questionnaires was completed (see "measures") during a regular class hour. A research assistant was available for questions and to ensure confidentiality and independent responding of the participants.

\section{Measures}

The Ruminative Response Scale (RRS; Nolen-Hoeksema and Morrow 1991; Dutch version: Raes et al. 2003) includes 22 items describing responses to depressed mood that are focused on depression symptoms and on the possible causes and consequences of dysphoric mood. Each item is rated on a four-point Likert type scale, ranging from 1 (almost never) to 4 (almost always). Total scores are calculated by summing the scores on the individual items. The RRS is a reliable and valid measure of rumination (see for an overview Luminet 2004).

The Beck Depression Inventory-II (BDI-II-NL; Beck et al. 1996; Dutch version: Van der Does, 2002) is a 21-item self-report depression inventory designed to assess symptoms and level of depression in adolescents and adults. The questionnaire consists of 21 items comprising a list of four statements each about a particular symptom of depression. The respondent has to choose the statement that best represented his or her mood during the last 2 weeks. The BDI-II-NL is a reliable and valid instrument of depressive symptomatology in adolescents (Ambrosini et al. 1991; Van der Does 2002).

The short version of the Inventory of Parent and Peer Attachment (IPPA; Armsden and Greenberg 1987: Dutch version: Muris et al. 2001) contains 28 items that apply to parents and 25 items that refer to peers. For both parents and peers, three scale scores are obtained (i.e., 
communication, trust, and alienation). The items that comprise the communication scale measure the quality and degree of spoken communication. The items which comprise the trust scale are indicative of mutual understanding and respect. The alienation scale represents anger and interpersonal isolation. Each item is rated on a four-point Likert type scale, labelled almost never or never, to almost always or always. The scores for the relevant items are added to obtain three attachment score for parents and peers each. Reliability and validity of the IPPA are well established (Gullone and Robinson 2005).

\section{Data Analysis}

The Statistical Package for Social Sciences (SPSS) was used for computing general descriptive information, internal consistency of the questionnaires, and correlation coefficients between questionnaire scores. Regression analyses were conducted to examine the relative contributions of quality of attachment relationship variables to explaining variance in levels of depressive symptoms. Only quality of attachment relationship variables that were significantly associated with symptoms of depression were included in the mediational analyses. For the mediation analysis, a distinction can be made between various effects and their corresponding weights. The total effect (weight $c$ ) of an independent variable (IV) on a dependent variable (DV) is composed of a direct effect (weight $c^{\prime}$ ) of the IV on the DV and an indirect effect (weight $a^{*} b$ ) of the IV on the DV through a proposed mediator (M). Weight $a$ represents the effects of the IV on the M, whereas weight $b$ is the effect of the M on the DV, partialling out the effect of the IV. More specifically, an indirect effect is the multiplication of the unstandardized regression weight of the IV on the $\mathrm{M}$ and the weight of the $\mathrm{M}$ on the DV.

The current study employed a bootstrapping method (with $N=5,000$ bootstrap resamples) to assess the indirect effects (see Preacher and Hayes 2008). Bootstrapping is a nonparametric resampling procedure that generates an empirical approximation of the sampling distribution of a statistic from the available data. More specifically, the bootstrapping sampling distributions of the indirect effects are empirically generated by taking a sample (with replacement) of size $N$ from the full data set and calculating the indirect effects in the resamples. This way, point estimates and 95\%-confidence intervals are estimated for the indirect effects. Three types of confidence intervals were computed (i.e., percentile confidence interval, biascorrected confidence interval and bias-corrected and accelerated confidence interval). As a stringent test of our hypotheses, we considered point estimates of indirect effects significant in the case zero is not contained in all confidence intervals.

\section{Results}

General Results

Before addressing the main results, some remarks need to be made. First, as can be seen in Table 1, the internal consistency of the IPPA scales representing alienation to caregivers and peers, were moderate at best, which can be attributed to the relatively few items that comprise these scales. Alternatively, it may be that these scales are heterogeneous in the sense that some items may apply to an adolescent whereas others not. Second, depression scores were not normally distributed with skewness and kurtosis outside the acceptable range of -1 to +1 . A square-root transformation of BDI scores was successful in "normalizing" the total depression scores.

Associations Between Quality of Attachment Relations, Rumination, and Depressive Symptoms

Table 2 presents the Pearson correlation coefficients between the various self-report measures. The level of depressive symptoms was significantly associated with rumination and with all indices of quality of attachment relations, except for communication with peers. A similar pattern of findings was found for rumination. With respect to the quality of attachment relations with parents and peers, all variables were significantly interrelated in the hypothesized directions.

To examine the relative contributions of indices of quality of attachment relations with parents and peers, to explaining variance in depressive symptoms, we performed a regression analysis. All variables were entered at the same time and only variables that were significantly $(p<.01)$ associated with depressive symptoms were used for further analysis. Three quality of attachment variables (i.e., trust in parents, communication with peers, and alienation from peers) accounted for a significant portion of the variance in depression symptoms and were included in the mediation analysis. Note that variance inflation factors (VIF) ranged between 1.65 and 4.27 indicating that multicollinearity did not influence the results.

\section{Mediation}

The results of the mediation analyses are presented in Table 3. As expected, the quality of attachment variables were significantly associated with depression scores ( $c$ weights) and also with rumination ( $a$ weights). With respect to the effects of the mediator on depression ( $b$ weights), results showed that rumination was positively and significantly related to symptoms of depression. In 
Table 1 General descriptive information and sex differences for the various questionnaires

\begin{tabular}{|c|c|c|c|c|c|c|c|}
\hline \multirow[b]{2}{*}{ Self-report measure } & \multicolumn{3}{|c|}{ Total group $(N=455)$} & \multicolumn{2}{|c|}{ Boys $(N=201)$} & \multicolumn{2}{|c|}{ Girls $(N=254)$} \\
\hline & $M$ & SD & Alpha & $M$ & SD & $M$ & $\mathrm{SD}$ \\
\hline BDI-II & 5.67 & 5.39 & .86 & 4.70 & 4.22 & 6.44 & 6.07 \\
\hline RRS & 30.33 & 7.81 & .91 & 28.76 & 6.28 & 31.58 & 8.64 \\
\hline \multicolumn{8}{|l|}{ IPPA parents } \\
\hline Communication & 21.86 & 4.45 & .81 & 21.74 & 4.07 & 21.96 & 4.74 \\
\hline Trust & 72.29 & 9.14 & .82 & 71.34 & 8.65 & 73.04 & 9.46 \\
\hline Alienation & 9.82 & 2.88 & .58 & 9.70 & 2.68 & 9.92 & 3.03 \\
\hline \multicolumn{8}{|l|}{ IPPA peers } \\
\hline Communication & 29.28 & 6.20 & .91 & 25.71 & 5.82 & 32.10 & 4.90 \\
\hline Trust & 52.87 & 5.79 & .90 & 51.00 & 5.88 & 54.35 & 5.28 \\
\hline Alienation & 11.08 & 2.99 & .56 & 11.08 & 2.86 & 11.07 & 3.10 \\
\hline
\end{tabular}

BDI-II, Beck Depression Inventory; RRS, Ruminative Response Scale; IPPA, Inventory of Parent and Peer Attachment

Table 2 Correlation coefficients between the various questionnaires

\begin{tabular}{|c|c|c|c|c|c|c|c|c|}
\hline & & 1. & 2. & 3. & 4. & 5. & 6. & 7. \\
\hline 1. & BDI-II & - & & & & & & \\
\hline \multirow[t]{2}{*}{2.} & RRS & $.67 *$ & - & & & & & \\
\hline & IPPA parents & & & & & & & \\
\hline 3. & Communication & $-.36^{*}$ & $-.23 *$ & - & & & & \\
\hline 4. & Trust & $-.47 *$ & $-.32 *$ & $.58^{*}$ & - & & & \\
\hline \multirow[t]{2}{*}{5.} & Alienation & $.39 *$ & $.33 *$ & $-.49 *$ & $-.50 *$ & - & & \\
\hline & IPPA peers & & & & & & & \\
\hline 6. & Communication & .03 & .05 & $.26^{*}$ & $.18^{*}$ & -.04 & - & \\
\hline 7. & Trust & $-.26^{*}$ & $-.22 *$ & $.26^{*}$ & $.38^{*}$ & $-.21 *$ & $.64 *$ & - \\
\hline 8. & Alienation & $.45^{*}$ & $.47 *$ & $-.25^{*}$ & $-.39 *$ & $.40 *$ & $-.17^{*}$ & $-.48^{*}$ \\
\hline
\end{tabular}

BDI-II, Beck Depression Inventory; RRS, Ruminative Response Scale; IPPA, Inventory of Parent and Peer Attachment

$* p<.01$

subsequent analyses, rumination partially mediated the relation between trust in parents and symptoms of depression and the relation between alienation from peers and symptoms of depression. In two subsequent analyses, alienation from peers and respectively parents did not mediate the relation between rumination and symptoms of depression. Full mediation was found for the relation between communication with peers and depression. Surprisingly, communication with peers was positively associated with depressive symptoms. The models accounted for $50 \%$ of the variance in depression scores. Further, one may argue that multicollinearity between the independent variables might have affected the results of the analyses. Therefore, we ran a linear regression analysis with depression scores as the dependent variable and the indices of attachment relationship variables as the independent variables. Variance inflation factors (VIF) ranged between 1.05 and 1.20 indicating that multicollinearity did not influence the results.

\section{Discussion}

This study sought to examine the links between quality of attachment relations with parents and peers, rumination, and depressive symptoms in a non-clinical sample of adolescents. More specifically, a mediational model was proposed in which rumination was hypothesized to mediate the relation between quality of attachment relations and symptoms of depression. Alienation was also tested as a mediator in the relation between rumination and depressive symptoms. Results can be summarized as follows. First, most indices of quality of attachment relations were associated with rumination and depression. Second, in examining the relative contribution the indices of quality of attachment relations to explaining variance in depression scores, parental trust, alienation from peers, communication with peers were significantly associated. Finally, full mediation was found for rumination in the relation between communication with peers and depressive symptoms, 
Table 3 Summary of mediation results $(5,000$ bootstrap samples, $N=455)$

\begin{tabular}{|c|c|c|c|c|c|c|c|c|}
\hline & $\begin{array}{l}\text { Independent } \\
\text { variable (IV) }\end{array}$ & $\begin{array}{l}\text { Mediating } \\
\text { variable }(\mathrm{M})\end{array}$ & $\begin{array}{l}\text { Dependent } \\
\text { variable (DV) }\end{array}$ & $\begin{array}{l}\text { Effect of IV on } \\
M \text { (a) }\end{array}$ & $\begin{array}{l}\text { Effect of } M \text { on } \\
\text { DV (b) }\end{array}$ & $\begin{array}{l}\text { Direct } \\
\text { effects (c') }\end{array}$ & $\begin{array}{l}\text { Indirect effect } \\
\left(a^{*} b\right)\end{array}$ & $\begin{array}{l}\text { Total } \\
\text { effects (c) }\end{array}$ \\
\hline 1. & Trust parents & Rumination & Depression & $-.19^{*}$ & $.49 *$ & $-.27 *$ & $-.09^{\mathrm{a}}$ & $-.36^{*}$ \\
\hline 2. & Alienation peers & Rumination & Depression & $.41 *$ & $.49 *$ & $.13 *$ & $.20^{\mathrm{a}}$ & $.33 *$ \\
\hline 3. & $\begin{array}{l}\text { Communication } \\
\text { peers }\end{array}$ & Rumination & Depression & $.16^{*}$ & $.49 *$ & .07 & $.08^{\mathrm{a}}$ & $.15^{*}$ \\
\hline
\end{tabular}

$I V$, independent variable; $D V$, dependent variable; $M$, mediator. In all three analyses, the effects of the other independent variables were controlled for

a Significant point estimate

$* p<.05$

whereas partial mediation for rumination was found in the relations between parental trust and alienation from peers, and symptoms of depression.

Rumination was found to fully mediate the relation between communication with peers and depression and to partially mediate the relation between parental trust and alienation from peers on the one hand and symptoms of depression on the other hand. Surprisingly, with respect to communication with peers, a positive association was found for this variable with symptoms of depression, whereas the zero-order correlation with depression was near to zero. A negative association between this communication with peers and depressive symptoms might be captured within the shared variance of communication with peers and the remaining two attachment scales (i.e., parental trust and alienation from peers) as this negative association should explain, together with the positive association found in the mediation analysis (which is the relative contribution of communication with peers to explaining variance in depression symptoms), the near to zero correlation between communication with peers and symptoms of depression. Thus, communication to peers seems to have two faces here: adolescents may communicate either more or less when feeling depressed. In explaining the positive relation between communication with peers and symptoms of depression, it may be that communication among adolescents may take the form of rumination on stressful events and negative consequences of one's mood, which may be positively related to depressive symptoms. In the friendship literature, Rose (2002) has introduced the concept of co-rumination, which refers to excessively discussing problems with friends and is proposed to contribute both to positive friendship adjustment, but also to problematic emotional adjustment (e.g., depressive symptomatology). Research findings pertaining to the relation between co-rumination and depressive symptoms remain, however, inconclusive (Rose 2002; Rose et al. 2007; Starr and Davila 2009).

Rumination partially mediated the relation between alienation from peers and depression, but alienation did not mediate the relation between rumination and symptoms of depression. These findings partly concur with Abela et al. (2004) who found mediation in both directions for social support (instead of alienation). Although high social support is associated with lower feelings of alienation (e.g., Fleming et al. 1982), it may be the case that once adolescents start to ruminate they communicate to peers about it (e.g., co-rumination) rather than perceiving the social environment as negative and consequently make less attempts to seek out for social support. An intriguing question here is in what way co-rumination takes place in adolescents. In this context, rumination has also been found to mediate the relation between depression and excessive reassuring seeking behaviours (Weinstock and Whisman 2006). These behaviours may serve the purpose of managing feelings of low self-worth and depression, but may eventually lead to interpersonal rejection, resulting in alienation. Thus, although speculative, it may be that excessive reassurance seeking fuels the process of alienation by facilitating interpersonal rejection.

Partial mediation was found between parental trust and symptoms of depression. This finding underscores the importance of the parents even in middle and late adolescence and adds to previous research suggesting that parents still serve as secure base for their children (e.g., Fraley and Davis, 1997; Nickerson and Nagle 2005). The finding of partial mediation suggests that no or little trust in parents is associated with depressive symptoms directly as well as indirectly through rumination. It is generally believed that trust in parents serves as a foundation for fulfilling the basic needs of children such as sense of safety, connectedness to others, self-esteem, and autonomy. If these needs cannot be fulfilled, youngsters may apply a number of coping strategies in order to deal with this. As such, rumination might be considered one cognitive coping strategy associated with depressed mood (see NolenHoeksema 1998).

Although the current study used non-clinical adolescents, the findings may tentatively have some clinical implications. A meta-analysis by Weisz et al. (2006) has 
shown that the mean effect size generated by treatments for juvenile depression was .34 indicating small to medium effect (Cohen 1988), and leaving room for improvement such as the inclusion of parents in treatment. However, on the basis of a review of family factors involved in the treatment of depression in youth, Sander and McCarthy (2005) have concluded that the effectiveness of treatments that involve children and adolescents exclusively is almost similar to that of treatments that include parents as well. The authors did conclude that it is important to disentangle specific components of treatment that produce successful results in terms of symptom reduction or relapse prevention. The results from our study provide a more detailed picture of what factors might be good candidates. An important tenet of depression treatment might be the inclusion of parental bonds (i.e., interaction between youngster and the parents). For example, Diamond et al. (2003) describes the Attachment-Based Family Treatment (ABFT) which is a brief, manualized treatment model tailored to the specific needs of depressed adolescents and their families. Attachment theory serves as the main theoretical framework to guide the process of repairing relational ruptures and rebuilding trustworthy relationships. There is an ongoing randomized clinical trial that assesses the effects of an ABFT-based treatment of which the first preliminary findings seem promising.

Interpersonal psychotherapy (IPT) for depressed adolescents includes the family context as well, but also takes peer relationships into account. IPT was originally developed by Klerman and colleagues (1984) and adapted for adolescents by Mufson and colleagues (1993). The adaptation for adolescents include developmental issues such as separation from parents, exploration of authority in relationships to parents, development of dyadic interpersonal relationships, initial experience with the death of relative or friend, peer pressure, and the single parent family. Results from a clinical trial have shown that IPT for depressed adolescents leads to a decrease in depressive symptoms and greater improvement in overall social functioning, functioning with friends, and specific problem-solving skills compared to controls (Mufson et al. 1999). Another interpersonal view on depression proposes that adolescent depression may be associated with an adolescent's failure to negotiate autonomy from parents while maintaining closeness and intimacy (Allen and Land 1999; Powers and Welsh 1999).

In addition to targeting family factors in treatment, it may also be important to target rumination in treatment. Recently, rumination focused cognitive-behavioural therapy (RFCBT) has been developed as a treatment form for chronic and recurrent depression. In this treatment, rumination is conceptualized as a form of avoidance and is replaced with more helpful approach behaviours. Recent experimental research suggests that there are distinct styles of rumination. Concrete process-focused rumination is considered a helpful style, whereas abstract, evaluative thinking is thought of as a maladaptive style (see Watkins et al. 2007; Watkins 2008). A number of techniques can be used to stimulate concrete, process-focussed rumination and to reduce abstract, evaluative thinking. Thus, RFBCT places a greater emphasis on the modification of the process of thinking rather than attempting to change the content of thoughts as is done in standard cognitive-behaviour therapy.

This study suffered from a number of shortcomings. First, the study is cross-sectional in nature making it impossible to draw any conclusion about cause-effect relationships. The mediation analysis should be interpreted with some caution. That is, one can only speak in terms of indirect effects. Longitudinal research may shed some light on temporal relationships between attachment, rumination, and symptoms of depression, whereas experimental studies may gain insight into the causal mechanisms by which attachment variables may influence depressive symptoms through rumination. Second, no information with regard to socioeconomic status and family composition were collected. However, the sample was representative of the various school levels, indicating that the current study included adolescents who are functioning at different levels. Finally, the study relied solely on self-report questionnaires. Future research should include other methods as well such as observational procedures to obtain information about the quality of the interaction between youngsters and their parents. Despite these limitations, the present study adds to our understanding of contributing and mediating mechanisms in relation to depressive symptoms in adolescents. It clearly advocates a theoretical point of view and clinical practice that highlights the importance of the complex relationships between quality of attachment relations with parents and peers, rumination, and depressive symptoms.

Acknowledgments This research was supported by an Innovational Research Incentive VENI grant (451-05-019) of the Foundation for Behavioural and Educational Sciences of the Netherlands Organization for Scientific Research (NWO), awarded to the second author.

Open Access This article is distributed under the terms of the Creative Commons Attribution Noncommercial License which permits any noncommercial use, distribution, and reproduction in any medium, provided the original author(s) and source are credited.

\section{References}

Abela, J. R. Z., Vanderbilt, E., \& Rochon, A. (2004). A test of the integration of the response styles theory and social support theories of depression in third and seventh grade children. Journal of Social and Clinical Psychology, 5, 653-674. 
Allen, J. P., \& Land, D. (1999). Attachment in adolescence. In J. Cassidy \& P. R. Shaver (Eds.), Handbook of attachment theory and research. Guilford: New York.

Ambrosini, P. J., Metz, C., Bianchi, M. D., Rabinovich, H., \& Undie, A. (1991). Concurrent validity and psychometric properties of the beck depression inventory in outpatient adolescents. Journal of the American Academy of Child and Adolescent Psychiatry, 30, 51-57.

Armsden, G. C., \& Greenberg, M. T. (1987). The inventory of parent and peer attachment: Individual differences and their relationship to psychological well-being in adolescence. Journal Youth Adolescence, 16, 427-454.

Armsden, G. C., McCauley, E., Greenberg, M. T., Burke, P. M., \& Mitchell, J. R. (1990). Parent and peer attachment in early adolescent depression. Journal of Abnormal Child Psychology, $18,683-697$.

Beck, A. T., Steer, R. A., \& Brown, G. K. (1996). Manual for the beck depression inventory ( $2 \mathrm{nd}$ ed.). San Antonio, TX: The Psychological Corporation.

Birmaher, B., Ryan, N. D., Williamson, D. E., Brent, D. A., Kaufman, J., Dahl, R. E., et al. (1996). Childhood and adolescent depression: A review of the past 10 years. Part I. Journal of the American Academy of Child and Adolescent Psychiatry, 35, 1427-1439.

Bowlby, J. (1973). Attachment and loss: Vol. II. Separation: Anxiety and Anger. London: Hogarth.

Bowlby, J. (1988). A secure base: Parent-child attachment and healthy human development. New York: Basic Books.

Cohen, J. (1988). Statistical power analysis for the behavioural sciences. 2. Hillsdale, NJ: Erlbaum.

Diamond, G., Siqueland, L., \& Diamond, G. M. (2003). Attachmentbased family therapy for depressed adolescents: Programmatic treatment development. Clinical Child and Family Psychology Review, 6, 107-127.

Dunn, V., \& Goodyer, I. M. (2006). Longitudinal investigation into childhood- and adolescence-onset depression: Psychiatric outcome in early adulthood. British Journal of Psychiatry, 188, 216-222.

Fleming, R., Baum, A., Gisriel, M. M., \& Gatchel, R. J. (1982). Mediating influences of social support on stress at Three Mile Island. Journal of Human Stress, 8, 14-22.

Fombonne, E., Wostear, G., Cooper, V., Harrington, R., \& Rutter, M. (2001). The Maudsley long-term follow-up of child and adolescent depression. 1. Psychiatric outcomes in adulthood. British Journal of Psychiatry, 179, 210-217.

Fraley, R. C., \& Davis, K. E. (1997). Attachment formation and transfer in young adults' close friendships and romantic relationships. Personal Relationships, 4, 131-144.

Green, J., \& Goldwyn, R. (2002). Attachment disorganisation and psychopathology: New findings in attachment research and their potential implications for developmental psychopathology in childhood. Journal of Child Psychology and Psychiatry, 43, 835-846.

Greenberg, M. T. (1999). Attachment and psychopathology in childhood. In J. Cassidy \& P. R. Shaver (Eds.), Handbook of attachment. Theory, research, and clinical applications (pp. 469-496). New York: Guilford Press.

Gullone, E., \& Robinson, K. (2005). The inventory of parent and peer attachment-revised (IPPA-R for children: A psychometric investigation. Clinical Psychology and Psychotherapy, 12, 67-79.

Hazan, C., \& Zeifman, D. (1994). Sex and the psychological tether. In K. Bartholomew \& D. Perlman (Eds.), Advances in personal relationships. Vol. 5. Attachment processes in adulthood (pp. 151-177). London: Jessica Kingsley.
Klerman, G. L., Weissman, M. M., Rounsaville, B. J., \& Chevron, E. S. (1984). Interpersonal psychotherapy of depression. New York, NY: Basic Books.

Luminet, O. (2004). Measurement of depressive rumination and associated constructs. In C. Papageorgiou \& A. Wells (Eds.), Depressive rumination. Nature, theory and treatment (pp. 187215). Chichester: Wiley.

Margolese, S. K., Markiewicz, D., \& Doyle, A. B. (2005). Attachment to parents, best friend, and romantic partner: Predicting different pathways to depression in adolescence. Journal of Youth and Adolescence, 34, 637-650.

Mufson, L., Moreau, D., Weissman, M. W., \& Klerman, G. L. (1993). Interpersonal psychotherapy for depressed adolescents. New York, NY: Guilford Press.

Mufson, L., Weissman, M. W., Moreau, D., \& Garfinkel, R. (1999). Efficacy of interpersonal psychotherapy for depressed adolescents. Archives of General Psychiatry, 56, 573-579.

Muris, P., Meesters, C. M. G., van Melick, M., \& Zwambag, L. (2001). Self-reported attachment style, attachment quality, and symptoms of anxiety and depression in young adolescents. Personality and Individual Differences, 30, 809-818.

Nickerson, A., \& Nagle, R. J. (2005). Parent and peer relations in middle childhood and early adolescence. Journal of Early Adolescence, 25, 223-249.

Nolen-Hoeksema, S. (1991). Responses to depression and their effects on the duration of depressive episodes. Journal of Abnormal Psychology, 100, 569-582.

Nolen-Hoeksema, S. (1998). The other end of the continuum: The costs of rumination. Psychology Inquiry, 9, 216-219.

Nolen-Hoeksema, S., \& Morrow, J. (1991). A prospective study of depression and posttraumatic stress symptoms after a natural disaster: The 1989 Loma Preita earthquake. Journal of Personality and Social Psychology, 61, 115-121.

Powers, S. I., \& Welsh, D. P. (1999). Mother-daughter interactions and adolescent girls' depression. In M. Cox \& J. Brooks-Gunn (Eds.), Conflicts and closeness: The formation, functioning and stability of families. Mahwah, NJ: Erlbaum.

Preacher, K. J., \& Hayes, A. F. (2008). Asymptotic and resampling strategies for assessing and comparing indirect effects in multiple mediator models. Behavior Research Methods, 40, 879-891.

Raes, F., Hermans, D., \& Eelen, P. (2003). The dutch version of the ruminative response scale (RRS-NL) and the rumination on sadness scale (RSS-NL). Gedragstherapie, 36, 97-104.

Rood, L., Roelofs, J., Bögels, S. M., Nolen-Hoeksema, S., \& Schouten, E. (2009). The influence of emotion-focused rumination and distraction on depressive symptoms in non-clinical youth: A meta-analytic review. Clinical Psychology Review, 29, $607-616$

Rose, A. J. (2002). Co-rumination in the friendships of girls and boys. Child Development, 73, 1830-1843.

Rose, A. J., Carlson, W., \& Waller, E. M. (2007). Prospective associations of co-rumination with friendship and emotional adjustment: Considering the socioemotional trade-offs of corumination. Developmental Psychology, 43, 1019-1031.

Sander, J. B., \& Mc Carty, C. A. (2005). Youth depression in the family context: Family risk factors and models of treatment. Clinical Child and Family Psychology Review, 8, 203-219.

Spasojevic, J., \& Alloy, L. B. (2002). Who becomes a depressive ruminator? Developmental antecedents of ruminative response style. Journal of Cognitive Psychotherapy, 16, 405-419.

Starr, L. R., \& Davila, J. (2009). Clarifying co-rumination: Associations with internalizing symptoms and romantic involvement among adolescent girls. Journal of adolescence, 32, 19-37. 
Van der Does, A. J. W. (2002). Handleiding bij de Nederlandse versie van beck depression inventory-second edition (BDI-II-NL). Amsterdam, NL: Harcourt.

Watkins, E. (2008). Constructive and unconstructive repetitive thoughts. Psychological Bulletin, 134, 163-206.

Watkins, E., Scott, J., Wingrove, J., Rimes, K., Bathurst, N., Steiner, H., et al. (2007). Rumination-focused cognitive behaviour therapy for residual depression: A case series. Behaviour Research and Therapy, 45, 2144-2154.
Weinstock, L. M., \& Whisman, M. A. (2006). Rumination and excessive reassurance-seeking in depression: A cognitiveinterpersonal integration. Cognitive Therapy and Research, 31, 333-342.

Weisz, J. R., McCarthy, C. A., \& Valeri, S. M. (2006). Effects of psychotherapy for depression in children and adolescents: A meta-analysis. Psychological Bulletin, 132, 132-149. 